\title{
CARTA DEL DIRECTOR
}

Constituye una satisfacción y un alto honor presentar el primer número de la revista "Policía y Seguridad Pública", un esfuerzo académico de la Academia Nacional de Seguridad Pública ANSP, a través de su Centro de Investigación Científica CINC, creado durante la presente administración. Este proyecto de publicación, el primero en su género en la historia de la ANSP, se enmarca en los desafios de la modernización y excelencia académica de esta entidad dedicada a la formación policial. Recoge en su espíritu el imperativo de rehabilitación de la investigación según se establece en el literal "c" del artículo 3 de la Ley Orgánica de la ANSP. Pero más que una demanda institucional, está planteando la articulación de esquemas de trabajo favorables a los estudios especializados de los problemas de la sociedad salvadoreña y su entorno en materia de justicia, seguridad y convivencia.

El contexto del bicentenario del primer grito de independencia de nuestra República nos recuerda que la búsqueda de soluciones para los problemas de violencia, merece la exploración de nuevos caminos, estimulando en el proceso la liberación de toda la creatividad e iniciativa del pensamiento estratégico contenido en la comunidad de pensadores para efectos de fortalecimiento de una mejor relación sistemática entre Estado y Sociedad.

Sin duda en esta publicación se ha logrado convocar a especialistas internacionales, académicos nacionales, pero más importante aún, incentivar la producción de la casa con la destacada participación de dos investigadores institucionales; poniendo de manifiesto la viabilidad de la cultura de investigación a todo nivel. La iniciativa se inscribe también en el esfuerzo general del gobierno actual bajo el cual han florecido otras iniciativas institucionales de naturaleza similar, formando parte de una búsqueda mejor diseñada para entender la realidad social.

La revista "Policía y Seguridad Pública" llenará un vacio de investigación sistemática en la materia descrita, pero a su vez marcará un antes y un después en cuanto a procesos reflexivos vinculados a las necesidades de transformación con significativa repercusión estructural. En definitiva una contribución patriótica para la actual generación en donde dadas las circunstancias de violencia, se esboza un planteamiento estratégico coincidente con la idea de retorno del Estado a la sociedad.

La investigación científica social por lo tanto debe adentrarse a la ruptura de visiones obsoletas, al cambio de paradigmas y a la adopción de posibilidades innovadoras, tal y como reza la visión de este proyecto editorial. En donde se procure el fortalecimiento institucional, tanto de la Academia Nacional de Seguridad Pública; como de la Policía Nacional Civil; abonando para que ambas impliquen una sinergia en el gabinete de Seguridad Pública, que lo estimule a actuar como un solo cuerpo. Además haga factible la procuración de diseños inteligentes en las políticas públicas, habilitando un flujo importante de insumos hacia los decisores, pero no con posturas cerradas, sino con variantes, alternativas y capacidades de autocorrección por parte de los entes públicos del ámbito de seguridad en un ejercicio de apropiamiento y responsabilidad. En general que alimente propuestas avanzadas, con carácter preventivo, mediante recursos viejos y nuevos, simples y complejos, convencionales y no convencionales; pero en substancia adaptables a las circunstancias y con propiedades creativas de evolución a las demandas de seguridad que traerán las coyunturas venideras. 
Carta

del Director

Finalmente hago un especial reconocimiento a la participación pionera de mujeres escritoras en esta publicación sin precedentes y a los esfuerzos del Centro de Investigación Científica a través de su equipo de trabajo para la materialización de apoyos, integrado en su totalidad por personal perteneciente al segmento de población joven. De este modo, la comunidad salvadoreña y extranjera, con vocación por la investigación científica en materia de de Policía y Seguridad Pública, cuanta ya con un espacio de expresión y publicación de sus trabajos. Todas y todos, hombres, mujeres, jóvenes, mayores, quedan convocados a sostener este esfuerzo con sus contribuciones. Para que esta nueva revista se conserve en el tiempo.

Jaime Edwin Martínez Ventura

Director General

Academia Nacional de Seguridad Pública 